\title{
A Few Remarks on 25 Years of The Geneva Association
}

\author{
by Reimer Schmidt*
}

In founding the Association, leading European insurers were pursuing two goals: an educational one for those actively researching and teaching economics, in particular concerning the changing parameters of insurance practice, and an ongoing programme of observation and analysis of scientific work on economics from the point of view of the insurance industry. However, it is not the task of a former Psresident to report in detail on the workings of the Association nor to honour its activities.

Today, anyone looking back at the development of this relationship over the last 25 years must surely be startled by the extent and frequency of change. The insurance industry pursued fundamental changes in direction, but was also influenced by shifts of emphasis in economic theories. Time and again it was insurance's security function that was not only an "overtone" in relation to the general development but at least provided a starting-point for planning to meet future developments. In this connection it goes without saying that everything covered by that umbrella term "Business Administration" is of central importance. Of particular significance were the concept of insurance as a risk transfer mechanism and the expansion of the service function, especially financial services, an area in which the Geneva Association has made a considerable contribution. Insurance business studies developed into a specialist area of business research and studies and the supervisory legislation of the EEC/EU received fruitful impulses from this source. Over the past decades articles published in the specialist insurance press dwelt above all on key issues of management theory, whereas major fundamental macroeconomic questions took a back seat. Thus, for example, whilst to date recognition of the effect and significance of "Information" has, for the private insurance sector, had the result of extending the disclosure duties of the insurer and formalising them in law, there has been no corresponding extension of the risk disclosure duties of the policy holders (or insureds) under existing insurance contract law.

\footnotetext{
${ }^{1}$ President of the Geneva Association from 1986-1990.
} 
When reviewing the development of the Geneva Association's activities over the last 25 years from the standpoint of the closing years of the century, it is possible to distinguish an initial phase still concerned with making good the consequences of the war in the field of academic research and the stabilisation of the industry. Thereafter there was a longer period concerned principally with EEC/EU questions. Here arguments about economic policy took precedence over the practical realisation of goals, liberalisation through step by step removal of restrictive regulations also leading to a redistribution of economic power. Initially the key issues were liberalisation and, consequentially, deregulation, with conflicts of opinion centering above all on their practical implementation. The principle of consumer protection - often (but without being properly thought through) seen only as the antithesis of liberalisation - led to a phase incorrectly named "re-regulation", that could in fact be more accurately described as "different regulation". However, these tensions helped prevent excesses of competition in this second and longer phase. At the same time increasing regulatory complexity coupled with the pluralistic behaviour of those operating in the market served to slow down creative market forces. Here a decisive factor was above all the fact that the coordination of trade and economic policy that the member states are obliged to pursue under the terms of the EEC/EU treaty has only occurred to a relatively very limited degree.

At the present time it is still somewhat difficult to see what economic policy and practical consequences the third phase of development will bring, the beginning of which lies in the twenty five years under consideration here. In the first place, here were the ideal conditions that are being created by the objectives of the international treaties of the WTO and the "GATT family" now applying to more than 130 member states. The concept of globalization sends out a special signal although in this new phase it is not so far linked to any fundamental measures other than the worldwide implementation of economic liberalisation. However, this global target clashes with the existing system of integration zones which are continuing to develop. In their individual ways, these partial markets were just as much precursors of liberalisation as, for example, in relation to its own member states has been the OECD, whose continued activity is an important factor in the development of international commercial law. The tension between the WTO and the integration zones is particularly apparent in the harmonisation measures of varying material content that states with dual membership of the WTO and an integration zone have to comply with or incorporate in their own legislation.

Consequently, many questions relating to economic issues and commercial law require "two track" answers. The foreign activities of businesses have in principle become more straightforward due to the WTO, but must from now on be considered in the light of the regulations of two economic areas (as well as having in addition to abide by the regulations of one individual state). For example, mergers and acquisitions of participations fall under two economic spheres, as do Conflict of Laws provisions in relation to insurance policies. To comply with WTO legislation, GATS does however contain certain provisions for the preservation of insurance supervision structured according to the protection principle.

In the EU integration zone there have also been changes in economic focus that have had direct economic and legal consequences for the private insurance sector. The role played by the USA through its participation in world trade, and in the creation of the 
WTO in particular, has an effect that goes beyond its economic impact as does its function in the day-to-day workings of this organisation. English as the language of science, technology and business, supported by the media, had a similar effect. For our industry, this applies to the form and interpretation of contracts, the construction of supervisory structures and the role of monopolies legislation.

It is not yet possible to judge to what degree the assimilation of such commercial and legislative processes will extend outside the areas of the individual integration zones. One could imagine that the use of directives to harmonise legislation - a method that plays a key role in the EU - could be replaced or supplemented by other instruments. The harmonisation process that is embedded in the EEC treaty is flawed not only because it creates a plethora of new laws but also because the import of the Community law can to some extent be changed in the process of conversion of the regulatory texts into the languages and individual national legal concepts of member states. One suggestion would be to create a 'loi uniforme' of insurance contract law, written in English and along the lines of the Incoterms, for example, at the same time confined to a greater degree to the most fundamental principles. Such a move would provide insurance contracts with an impartial position in international law and a suitable place in the framework of international commercial law. It is conceivable that other harmonisation procedures could apply in the integration zones if international insurance law contains a 'numerus clausus' of higher-ranking legal principles.

The great dynamism of the insurance markets will in future continue to give rise to a considerable requirement for technical clarification and scientific assessment. The rapid development of the ever expanding information society as well as matters ranging from underwriting questions to accounting systems, the standards for free capital and for special risk provisions of insurance companies all point in this direction. Intensity of competition will inevitably bring about greater discussion about what constitutes acceptable conduct, the common European currency and the special problems of the private insurance sector. It will also be necessary for insurance companies and their professional associations to pay considerable attention to the development of theoretical and political economics and sociology (including empirical sociological research), as the emphasis on the mental and physical capacities of employees necessitated by competition always brings with it the danger of disregarding changes in basic scientific knowledge. This particularly applies to a branch of the economy whose task it is to take on the risks of society as a whole as well as its private and commercial members, to assess changes in risk, to take into account loss prevention and reduction as well as alternative methods of risk coverage and to cultivate operational and technical management methods. Structural problems do not in fact arise out of an over-reliance on theory but from working on the basis of an incomplete economic and sociological conspectus. The Geneva Association has therefore plenty to think about ... 